\title{
PRODUÇÃO DE MUDAS E CRESCIMENTO INICIAL EM CAMPO DE Enterolobium contortisiliquum PRODUZIDAS EM DIFERENTES RECIPIENTES
}

\author{
Alan Henrique Marques de Abreu ${ }^{1}$, Paulo Sérgio dos Santos Leles², Lucas Amaral de Melo², \\ Dereck Halley Antony Alves Ferreira ${ }^{1}$, Flávio Augusto Santos Monteiro ${ }^{1}$

\begin{abstract}
1Universidade Federal Rural do Rio de Janeiro, Programa de Pós-Graduação em Engenharia Florestal, Seropédica, Rio de Janeiro, Brasil - alanhenriquem@gmail.com; dhaferreira@gmail.com; monteiro.flaviosantos@gmail.com

${ }^{2}$ Universidade Federal Rural do Rio de Janeiro, Departamento de Silvicultura, Seropédica, Rio de Janeiro, Brasil - pleles@ufrrj.br;
\end{abstract} \\ lucasamaral@ufrrj.br
}

Recebido para publicação: 14/09/2012 - Aceito para publicação: 10/06/2014

\begin{abstract}
O objetivo deste trabalho foi verificar a qualidade de mudas de Enterolobium contortisiliquum produzidas em sacos plásticos de $1.248 \mathrm{~cm}^{3}$, tubetes de $280 \mathrm{~cm}^{3}$ e tubetes de $180 \mathrm{~cm}^{3}$, e posteriormente avaliar a sobrevivência e o crescimento pós-plantio. Na fase de viveiro, todos os recipientes produziram mudas de qualidade, com destaque para as produzidas nos sacos plásticos. $\mathrm{Na}$ fase de campo, as plantas oriundas de saco plástico e de tubete $280 \mathrm{~cm}^{3}$ apresentaram $100 \%$ de sobrevivência, enquanto as de tubete de $180 \mathrm{~cm}^{3}$ apresentaram apenas $58 \%$. Apesar de as mudas produzidas em sacos plásticos apresentarem maiores medidas na época de plantio, constatou-se que essa diferença tende a diminuir ou desaparecer com o tempo, pois as mudas produzidas nos tubetes apresentaram maior crescimento relativo. Para produção de mudas de Enterolobium contortisiliquum, podem-se utilizar sacos plásticos com capacidade $1.248 \mathrm{~cm}^{3}$ ou tubetes de $280 \mathrm{~cm}^{3}$.
\end{abstract}

Palavras-chave: Tubetes; sacos plásticos; orelha-de-negro.

\begin{abstract}
Seedlings production and initial growth in fields of Enterolobium contortisiliquum produced in different containers. This research aims to verify the quality of Enterolobium contortisiliquum seedlings produced in plastic bags of $1.248 \mathrm{~cm}^{3}$, tubes of $280 \mathrm{~cm}^{3}$, and tubes of $180 \mathrm{~cm}^{3}$, as well as evaluate their survival and growth after planting. In nursery stage, all containers resulted in quality seedlings, especially those produced in plastic bags. In field phase, plants from plastic bag and tubes $280 \mathrm{~cm}^{3}$ had $100 \%$ survival, while to the ones from tube of $180 \mathrm{~cm}^{3}$ survival was only $58 \%$. Despite seedlings produced in plastic bags present greatest measures in planting season, such difference tends to disappear in time, because the seedlings grown in tubes had higher relative growth. We recommend plastic bags of $1.248 \mathrm{~cm}^{3}$ and tubes of $280 \mathrm{~cm}^{3}$.

Keywords: Tubes; plastic bags; orelha-de-negro.
\end{abstract}

\section{INTRODUÇÃO}

As matas ciliares desempenham um papel de suma importância para a manutenção dos recursos naturais, prestando valiosos serviços ambientais, como aumento da qualidade da água, estabilização das margens dos rios e servindo de hábitat para a fauna silvestre, entre outros. No entanto, ao longo dos anos, a pressão antrópica, por meio dos processos de urbanização, construção de estradas e atividades agropecuárias, resultou em uma intensa devastação, necessitando de ações para recuperação e preservação desses ambientes. Com o aumento da demanda por projetos dessa natureza, faz-se necessário aumentar a produção de mudas de espécies florestais nativas, de diferentes espécies, adaptadas às condições peculiares dos locais de plantio, com qualidade e preços competitivos.

Para recuperação de matas ciliares, estudos têm demonstrado que a seleção de espécies adaptadas às condições locais pode aumentar a sobrevivência em campo, assim como acelerar o processo de recomposição (LACERDA; FIGUEIREDO, 2009). Uma das espécies amplamente recomendadas para

FLORESTA, Curitiba, PR, v. 45, n. 1, p. 141 - 150, jan. / mar. 2015.

Abreu, A. H. M. de et al.

ISSN eletrônico 1982-4688 / ISSN impresso 0015-3826

141

DOI: $10.5380 /$ rf.v45i1.28931 
a recuperação de matas ciliares é Enterolobium contortisiliquum (AVILA et al., 2011; DURIGAN; SILVEIRA, 1999; MALAVASI et al., 2010; MARTINS, 2001), popularmente conhecida como orelhade-negro, pertencente à família Fabaceae. É uma espécie nativa da Mata Atlântica (LONGHI et al., 2000) e se destaca pela capacidade de adaptação em diferentes tipos de solo (LIMA et al., 2010).

Além de espécies adaptadas, outro fator que influencia no processo de recuperação de matas ciliares é a qualidade das mudas. Entre os fatores mais importantes para a produção de mudas de qualidade, encontra-se o tipo de recipiente. $\mathrm{Na}$ escolha do melhor recipiente, deve ser levada em consideração a quantidade de mudas e a espécie produzida, além da finalidade da produção (SILVA et al., 2007). Também deve ser considerado o custo com transporte das mudas até o local e a mão de obra envolvida na atividade de plantio.

Entre os recipientes mais utilizados para produção de mudas nativas da flora brasileira estão os tubetes e os sacos plásticos. Segundo Hahn et al. (2006), sacos plásticos necessitam de um investimento menor para produção, são facilmente preenchidos com substratos de fácil obtenção e não necessitam de mão de obra especializada. Por outro lado, os tubetes apresentam frisos verticais que direcionam o sistema radicial, evitando enovelamento e possuem um orifício na parte inferior que possibilita a poda natural das raízes pelo ar, além de possibilitar a automatização dos viveiros e apresentar melhores condições de ergonomia aos trabalhadores. Em geral, cada um desses recipientes apresenta potenciais vantagens e desvantagens, assim como requerem técnicas de produção diferentes. Geralmente são analisados como parâmetros comparativos entre produção de mudas em diferentes recipientes apenas o crescimento e a qualidade das mudas no viveiro, ignorando-se o principal objetivo, que é a resposta dessas mudas quando levadas para o plantio no campo.

O presente estudo tem como objetivo verificar a qualidade de mudas de Enterolobium contortisiliquum (orelha-de-negro) produzidas em sacos plásticos de 14 x $20 \mathrm{~cm}\left(1.248 \mathrm{~cm}^{3}\right)$ e em tubetes de 280 e $180 \mathrm{~cm}^{3}$, em fase de viveiro, e analisar a sobrevivência e o crescimento inicial dessas mudas em plantio de recuperação de mata ciliar.

\section{MATERIAL E MÉTODOS}

O trabalho foi desenvolvido em duas etapas: primeiro, a produção das mudas (fase de viveiro), realizada no período de setembro de 2010 a fevereiro de 2011, no Viveiro Florestal da Universidade Federal Rural do Rio de Janeiro, localizado no município de Seropédica, RJ. Em seguida, a segunda fase, que consistiu de plantio e avaliações de campo.

O clima de Seropédica, segundo a classificação de Köppen, é do tipo Aw (BRASIL, 1980). Segundo os dados dos últimos dez anos da estação meteorológica da PESAGRO-RJ, a mais próxima ao local do experimento, a precipitação média anual é de $1.248 \mathrm{~mm}$, sem estação seca definida, e a temperatura média anual é de $23,7^{\circ} \mathrm{C}$.

\section{Fase de viveiro}

O tratamento $T_{1}$ foi constituído por recipiente saco de plástico $14 \times 20 \mathrm{~cm}\left(1.248 \mathrm{~cm}^{3}\right)$ e por substrato formado por subsolo argiloso, composto orgânico e areia, na proporção volumétrica de 6:3:1, respectivamente. Para o tratamento $\mathrm{T}_{2}$, utilizou-se tubete com capacidade de $280 \mathrm{~cm}^{3}$ e substrato formado pela mistura de $90 \%$ de substrato comercial e $10 \%$ de argila. $\mathrm{O}$ tratamento $\mathrm{T}_{3}$ utilizou o mesmo substrato do tratamento $T_{2}$, porém em tubetes de $180 \mathrm{~cm}^{3}$. Para ambos os substratos, não foi realizada adubação de base. A utilização de duas composições de substratos se faz necessária devido às características técnicas de cada recipiente, como já evidenciado em outros trabalhos de pesquisa (BOMFIM et al., 2009; MESQUITA et al., 2011). Foram realizadas as análises químicas dos substratos pelo Laboratório de Análise de Solos Viçosa Ltda., cujos resultados encontram-se na tabela 1.

O delineamento estatístico foi o inteiramente casualizado, constituído de quatro repetições. Cada repetição foi formada por seis recipientes, contendo uma muda cada.

A semeadura foi realizada diretamente nos recipientes, utilizando-se três sementes por recipiente. Após a germinação, foi realizado o desbaste, deixando-se, sempre que possível, a plântula com maior vigor e mais centralizada do recipiente. As mudas foram mantidas em casa de sombra até os 25 dias após a semeadura e depois levadas a pleno sol. A irrigação foi realizada por sistema de microaspersão de uma a três vezes ao dia, dependendo das condições do clima (chuva, insolação e temperatura) e da fase de crescimento das mudas. 
Tabela 1. Características químicas dos substratos utilizados para produção de mudas de Enterolobium contortisiliquum.

Table 1. Chemical characteristics of the substrates used for seedling production Enterolobium contortisiliquum.

\begin{tabular}{|c|c|c|c|c|c|c|c|c|c|c|}
\hline \multirow{2}{*}{ Substrato } & $\mathbf{N}$ & $\mathbf{P}$ & $\mathbf{K}$ & $\mathbf{C a}$ & Mg & $\mathbf{F e}$ & Mn & $\mathbf{C u}$ & $\mathbf{Z n}$ & \multirow{2}{*}{ pH } \\
\hline & \multicolumn{5}{|c|}{...................................... \% \% ............................. } & \multicolumn{4}{|c|}{ 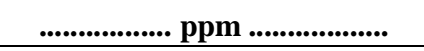 } & \\
\hline Saco plástico & 0,12 & 0,13 & 0,24 & 0,00 & 0,10 & 8.310 & 58 & 3 & 28 & 6,36 \\
\hline Tubete & 0,46 & 0,22 & 0,16 & 4,71 & 0,27 & 8.422 & 128 & 3 & 32 & 5,13 \\
\hline
\end{tabular}

Teores totais, determinados no extrato ácido (ácido nítrico com ácido perclórico); N: Método do Kjeldahl.

Quando as mudas produzidas em tubetes atingiram a altura média de $15 \mathrm{~cm}$, foi realizada a alternagem dos tubetes nas bandejas, reduzindo a densidade de mudas em $50 \%$ da inicial.

Aos 90 e 120 dias após a semeadura, foram realizadas adubações de cobertura nas mudas produzidas em tubetes. A adubação foi realizada à base de N-P-K (20-05-20), na dosagem de 0,1 grama por planta, diluída em solução de $10 \mathrm{ml}$, aplicada com auxílio de uma seringa. Para as mudas produzidas em sacos plásticos não foi necessário realizar a adubação de cobertura, pois as mudas não apresentaram sintomas visuais de deficiência nutricional.

Aos 150 dias após a semeadura, foram realizadas as mensurações da altura da parte aérea e do diâmetro do coleto. Foram selecionadas as três mudas com as dimensões mais próximas da média em cada tratamento, para mensuração da área foliar (aparelho LICOR-3600), peso de matéria seca da parte aérea e peso de matéria seca do sistema radicial. Todo o material foi acondicionado em sacos de papel, devidamente identificados e secos em estufa com circulação de ar interno à temperatura média de $65^{\circ} \mathrm{C}$, até a obtenção de peso constante.

Com base nos parâmetros morfológicos avaliados, foram calculadas a relação altura/diâmetro (H/D) e a relação entre massa seca radicial e massa seca da parte aérea (MSR/MSPA), além do índice de qualidade de Dickson (IQD).

Os dados obtidos foram submetidos ao teste de Liliefors e de Cochran e Bartlet, para testar, respectivamente, a normalidade e a homogeneidade das variâncias. Não havendo necessidade de transformações, foi realizada a análise de variância $(F<0,05)$ e posteriormente o teste de Tukey ao nível de significância de 5\%.

\section{Fase de campo}

Foi conduzida em área da Usina Termoelétrica Barbosa Lima Sobrinho, em plantio de recuperação das margens do Rio Guandu, no município de Seropédica, RJ, no período de fevereiro a julho de 2011. A área de plantio foi caracterizada como uma pastagem abandonada, com predominância de capim colonião (Panicum maximum). Possui topografia plana e o solo foi classificado, segundo Villa (2012), como Cambissolo háplico Tb distrófico, com horizonte A na camada até $18 \mathrm{~cm}$ de profundidade e $\mathrm{AB}$ de $19-30 \mathrm{~cm}$.

O balanço hídrico médio mensal foi calculado pelo método de Thornthwaite e Mather (1955), para a série histórica dos últimos 20 anos (janeiro de 1991 a dezembro de 2011) (Figura 1). Considerou-se $190 \mathrm{~mm}$ a capacidade de água disponível (CAD), correspondente ao Cambissolo háplico Tb distrófico, conforme descrito por Portugal et al. (2008) e utilizando-se a planilha eletrônica desenvolvida por Sentelhas et al. (1998). Constata-se que nos meses de maio a outubro há uma pequena deficiência hídrica no solo.

Após serem retirados os indivíduos para análise destrutiva, foram escolhidas 12 mudas com as dimensões em altura e diâmetro mais próximas da média, em cada tratamento, para o plantio em campo. $\mathrm{O}$ delineamento estatístico utilizado foi inteiramente casualizado, com quatro repetições, compostas por três mudas. Coletaram-se amostras de solo na profundidade de 0-20 e 20-40 cm, que foram enviadas para análise química em laboratório de análises de solos, cujos resultados encontram-se na tabela 2.

O espaçamento de plantio foi de 2,0 x 1,5 m. Realizou-se a abertura das covas com dimensões de $25 \times 25 \times 25 \mathrm{~cm}$, adubadas com $120 \mathrm{~g}$ de adubo N-P-K (06-30-06) por cova. Os tratos culturais envolveram o controle de formigas-cortadeiras com isca formicida à base de sulfuramida, desde 30 dias antes do plantio até 150 dias após o mesmo. O controle de plantas daninhas foi realizado pelo método de capinas na faixa de plantio, com faixas de 1,20 m de largura, ocorrendo em duas ocasiões. 


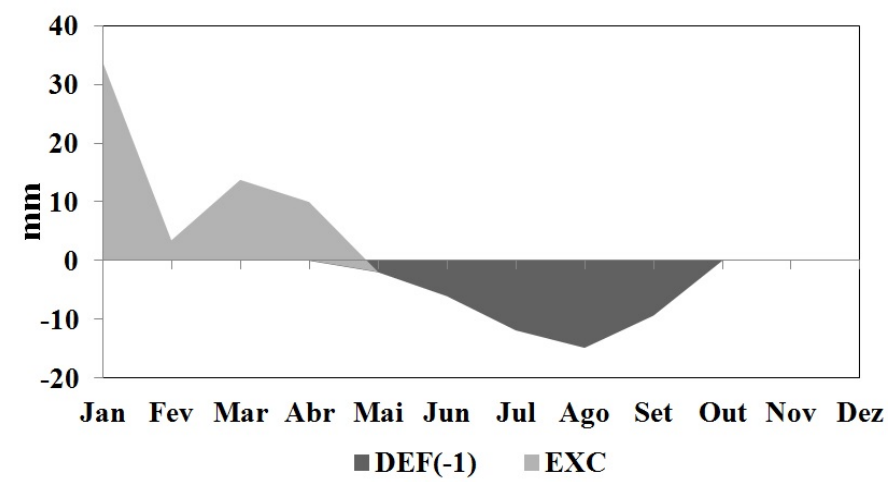

Figura 1. Extrato do balanço hídrico mensal da série histórica para o município de Seropédica, RJ.

Figure 1. Extract of monthly hydric balance, from historical series for the municipality of Seropédica, RJ.

Tabela 2. Análise de solo da área onde foi realizado o plantio das mudas de Enterolobium contortisiliquum.

Table 2. Soil analysis was conducted of the area where the planting of seedlings Enterolobium contortisiliquum.

\begin{tabular}{lccccccc}
\hline $\begin{array}{l}\text { Profundidade } \\
(\mathbf{c m})\end{array}$ & $\mathbf{p H}^{\mathbf{1}}$ & $\mathbf{P}^{2}$ & $\mathbf{K}^{2}$ & $\mathbf{A l}^{3}$ & $\mathbf{C a}^{3}$ & $\mathbf{M g}^{3}$ & \multirow{2}{*}{ Textura } \\
\hline $0-20$ & 5,2 & 4,8 & 132 & 0,5 & 1,2 & 1,1 & Argilosa \\
$20-40$ & 4,9 & 4,5 & 82 & 1,0 & 0,8 & 0,9 & Argilosa \\
\hline
\end{tabular}

${ }^{\mathrm{p}} \mathrm{pH}$ em água relação $1: 2,5 ;{ }^{2}$ extrator Mehlich ${ }^{-1} ;{ }^{3}$ extrator de $\mathrm{KCl} 1,0 \mathrm{~N}$.

As avaliações consistiram de medições da altura da parte aérea e do diâmetro ao nível do solo, no dia do plantio (tempo 0) e 150 dias após o plantio. Analisou-se também a taxa de sobrevivência aos 150 dias após o plantio. Com as avaliações em duas épocas, foi possível determinar o incremento (I) e a taxa de crescimento relativo das características analisadas (CR), pelas seguintes fórmulas (CARNEIRO, 1995):

$$
\begin{gathered}
\mathrm{I}=\text { Medida } 150 \text { dias após o plantio }- \text { Medida no plantio } \\
\mathrm{CR}(\%)=\frac{\text { Medida } 150 \text { dias após o plantio }- \text { Medida no plantio }}{\text { Medida no plantio }} * 100
\end{gathered}
$$

Os dados foram submetidos à análise de variância $(F<0,05)$. Quando foram detectadas diferenças significativas, os dados foram submetidos ao teste de Tukey, ao nível de 5\% de significância.

\section{RESULTADOS E DISCUSSÃO}

\section{Fase de viveiro}

As mudas produzidas em sacos plásticos, aos 150 dias após a semeadura, apresentaram altura da parte aérea $(\mathrm{H})$ superior às produzidas em tubetes de 280 e $180 \mathrm{~cm}^{3}$. Diferenças de altura entre as mudas produzidas nos tubetes de 280 e de $180 \mathrm{~cm}^{3}$ não foram significativas (Tabela 3). Esse comportamento de maior crescimento das mudas produzidas em sacos plásticos está provavelmente relacionado com o maior volume de substrato, o que propicia um maior espaço para o crescimento radicial e, segundo Lopes et al. (2005), normalmente oferece maiores quantidades de nutrientes e água. Assim, há um maior crescimento das mudas, já que elas tendem a balancear o crescimento do sistema radicial e da altura da parte aérea (CARNEIRO, 1995).

Em relação à característica diâmetro do coleto (DC), verifica-se que as mudas de Enterolobium contortisiliquum produzidas nos sacos plásticos apresentaram valores superiores às produzidas em tubetes, não havendo diferenças significativas entre estes últimos. Embora a altura e o diâmetro do coleto 
sejam importantes parâmetros morfológicos para definição da qualidade de mudas florestais, e os de mais fácil mensuração, não devem ser os únicos avaliados. Quanto mais parâmetros forem analisados, maior será a certeza de qualidade da muda produzida.

Tabela 3. Características de crescimento de mudas de Enterolobium contortisiliquum produzidas em diferentes recipientes, aos 150 dias após a semeadura.

Table 3. Growth characteristics of seedlings Enterolobium contortisiliquum produced in different containers, at 150 days after sowing.

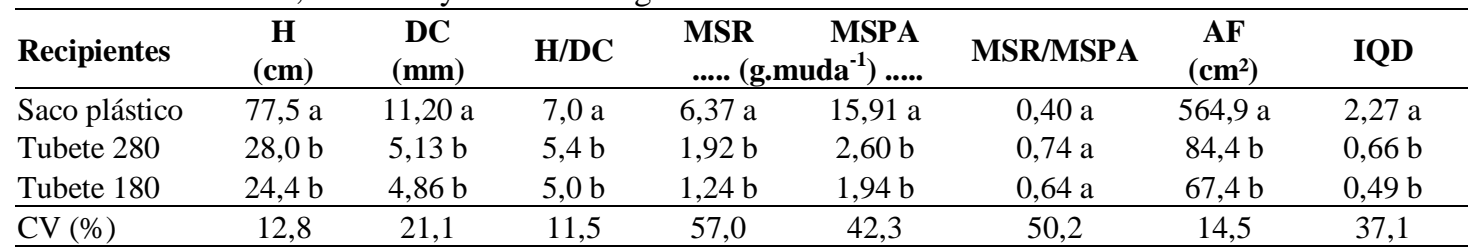

Médias seguidas da mesma letra, na coluna, não diferem entre si pelo teste de Tukey $(\mathrm{P}<0,05)$. H: altura da parte aérea; DC: diâmetro do coleto; H/DC: relação altura/diâmetro; MSR: massa seca radicial; MSPA: massa seca da parte aérea; MSR/MSPA: relação massa seca radicial e massa seca da parte aérea; AF: área foliar; IQD: índice de qualidade de Dickson; CV: coeficiente de variação.

A relação entre a altura e o diâmetro do coleto (H/DC), segundo Carneiro (1995), constitui um dos parâmetros mais usados para avaliar a qualidade de mudas florestais, pois, além de refletir o acúmulo de reservas, assegura maior resistência a períodos secos e melhor fixação no solo. As mudas apresentaram a relação H/DC abaixo de 10, padrão considerado bom (JOSÉ et al., 2005). Segundo os mesmos autores, mudas com alta relação H/DC podem apresentar estiolamento e menor índice de sobrevivência no campo, sendo que o tombamento decorrente dessa característica pode resultar em morte ou deformações das plantas no campo.

Para as mudas produzidas em sacos plásticos, foram encontrados valores médios de massa seca radicial (MSR) e massa seca da parte aérea (MSPA) significativamente superiores aos dos demais tratamentos. Esse resultado está ligado à tendência de menores volumes de recipiente restringirem o crescimento do sistema radicial das mudas, e como estas tendem a apresentar um crescimento balanceado entre a parte radicial e a aérea, o menor volume do recipiente também afeta o crescimento da parte aérea. Além disso, para a espécie Enterolobium contortisiliquum essa restrição imposta pelos recipientes de menor volume se torna mais acentuada, devido à autoecologia da espécie, que, segundo Duboc e Guerrini (2007) e conforme observado durante as avaliações, possui uma acentuada produção de nódulos no sistema radicial. Esses nódulos são responsáveis pela atividade simbiótica com bactérias fixadoras de nitrogênio, o que pode auxiliar na nutrição da muda durante o processo de produção.

A relação massa seca do sistema radicial e massa seca da parte aérea (MSR/MSPA) não diferiu significativamente, apesar de terem ocorrido diferenças significativas no peso seco da parte aérea e do sistema radicial das mudas produzidas nos diferentes recipientes. Isso pode ser explicado, de acordo com Reis et al. (1989) e Carneiro (1995), pelo ajuste de crescimento das mudas, no qual a restrição imposta pelo recipiente promove o crescimento balanceado entre as partes, sem alteração na distribuição relativa de matéria seca com a variação do volume do recipiente. José et al. (2005) também não constataram diferenças significativas dessa relação em mudas de Schinus terebinthifolius produzidas em volumes de tubetes de 50 e $150 \mathrm{~cm}^{3}$.

Em relação à área foliar (AF), constata-se que as mudas produzidas nos sacos plásticos apresentaram valores significativamente superiores aos dos tubetes. Esse parâmetro, entendido como a superfície fotossintetizante total da planta, tem sido considerado como um índice de produtividade, dada a importância dos órgãos fotossintetizantes na produção biológica (SCALON et al., 2006). No entanto, Souza (2011) alerta para o fato de que a maior área foliar também pode significar uma maior área susceptível à transpiração pós-plantio, assim como ocorre com mudas produzidas em condições de restrições de luminosidade, não sendo o melhor parâmetro de avaliação de qualidade de mudas florestais.

As mudas produzidas em saco plástico também apresentaram valores médios de índice de qualidade de Dickson (IQD) significativamente superiores aos dos tubetes. Segundo Gomes et al. (2003), quanto maior for esse valor dentro de um lote de mudas, melhor o padrão de qualidade, porém são 
necessários maiores estudos para a determinação de faixas de valores ótimos para mudas florestais nativas.

Com base nesses parâmetros, verifica-se que as mudas produzidas em sacos plásticos apresentaram parâmetros morfológicos de qualidade superiores às produzidas em tubetes de 280 e $180 \mathrm{~cm}^{3}$. É possível inferir também que todas as mudas dos diferentes tratamentos chegaram, aos 150 dias após a semeadura, aptas para a expedição, pois foram produzidas com métodos diferentes, que exigem padrões diferentes para expedição.

\section{Fase de campo}

No campo, após as mudas serem plantadas, os percentuais de sobrevivência observados, aos cinco meses após o plantio, foram de 100,100 e 58\% para as mudas provenientes de saco plástico, tubete de $280 \mathrm{~cm}^{3}$ e tubete de $180 \mathrm{~cm}^{3}$, respectivamente. Segundo Belloto (2010), taxa de mortalidade superior a $10 \%$ em reflorestamentos de espécies nativas demanda ações imediatas de replantio. Com base nesse critério, apenas as mudas produzidas nos tubetes de $180 \mathrm{~cm}^{3}$ não atenderam aos níveis aceitáveis de sobrevivência.

$\mathrm{Na}$ época do plantio, as mudas de Enterolobium contortisiliquum produzidas em sacos plásticos apresentavam altura significativamente superior às dos tubetes, e essa diferença se manteve cinco meses após o plantio. No entanto, quando se observa o incremento das características altura e diâmetro aos cinco meses após o plantio, pode-se notar que o incremento em altura foi maior nas plantas de mudas originárias de tubetes, e não houve diferenças estatísticas relativas ao incremento em diâmetro (Tabela 4). Isso se deve provavelmente à melhor formação do sistema radicial, propiciada pelas estrias presentes nos tubetes, que direcionam o sistema radicial. Com um sistema radicial bem formado, a muda apresenta uma maior eficiência na absorção dos nutrientes disponibilizados durante o plantio (CARNEIRO, 1995). Continuando assim, a tendência é que a diferença de altura entre as mudas produzidas em sacos plásticos e tubetes tendam a desaparecer gradativamente após o plantio no campo. Essa tendência já foi observada por José et al. (2005) para Schinus terebinthifolius, Malavasi e Malavasi (2006) para Cordia trichotoma e Jacaranda micranta, e Keller et al. (2009) para Inga marginata, Jacaranda puberula e Zeyheria tuberculosa.

Tabela 4. Características de crescimento de plantas de Enterolobium contortisiliquum oriundas de três recipientes, em plantio de recuperação de mata ciliar do rio Guandu, município de Seropédica, RJ.

Table 4. Growth characteristics of plants Enterolobium contortisiliquum, from three containers, planting riparian vegetation recovery in Guandu River, municipality of Seropédica, RJ.

\begin{tabular}{|c|c|c|c|c|c|c|c|}
\hline Recipientes & $\begin{array}{r}\text { H } 0 \\
\quad \ldots . . . . \\
\end{array}$ & $\begin{array}{c}\text { H } 150 \\
\ldots . . .(\mathbf{c m}) \\
\end{array}$ & I. Alt. & $\begin{array}{c}\text { Cresc. Rel. } \\
(\%)\end{array}$ & $\begin{array}{r}\text { DNS0 } \\
\ldots . . . . . . . . \\
\end{array}$ & $\begin{array}{r}\text { DNS } 150 \\
\ldots(\mathrm{mm}) \ldots\end{array}$ & $\begin{array}{l}\text { I. DNS } \\
\ldots \ldots \ldots . . .\end{array}$ \\
\hline Saco plástico & $73,3 \mathrm{a}$ & $91,4 \mathrm{a}$ & $18,1 \mathrm{~b}$ & $25,7 \mathrm{~b}$ & $11,7 \mathrm{a}$ & $20,0 \mathrm{a}$ & $8,3 \mathrm{a}$ \\
\hline Tubete 280 & $28,3 \mathrm{~b}$ & $59,1 \mathrm{~b}$ & $30,8 \mathrm{a}$ & $109,8 \mathrm{a}$ & $5,1 \mathrm{~b}$ & $16,4 \mathrm{ab}$ & $9,0 \mathrm{a}$ \\
\hline Tubete 180 & $23,8 \mathrm{~b}$ & $56,8 \mathrm{~b}$ & $33,0 \mathrm{a}$ & $139,7 \mathrm{a}$ & $5,1 \mathrm{~b}$ & $14,1 \mathrm{~b}$ & $11,3 \mathrm{a}$ \\
\hline $\mathrm{CV}$ & 12,1 & 24,0 & 61,1 & 63,8 & 21,1 & 30,7 & 49,3 \\
\hline
\end{tabular}

Médias seguidas da mesma letra, na coluna, não diferem entre si, pelo teste de Tukey ( $<$ < 0,05). H 0: altura de plantio; H 150: altura 150 dias após o plantio; I. Alt: incremento em altura; Cresc. Rel.: crescimento relativo; DNS 0: diâmetro ao nível do solo no plantio; DNS 150: diâmetro ao nível do solo 150 dias após o plantio; I. DNS: incremento em diâmetro ao nível do solo; CV: coeficiente de variação.

Conforme se observa na tabela 4, as mudas provenientes dos tubetes de 280 e $180 \mathrm{~cm}^{3}$ apresentaram maior crescimento relativo (Cresc. Rel.). Esse resultado pode ser explicado, segundo Reis $e t$ al. (1989), pelo fato de que, normalmente, mudas produzidas em condições de restrição radicial, como as dos tubetes, passam por um processo de rustificação no viveiro, além de apresentarem uma melhor arquitetura do sistema radicial, devido às características inerentes ao próprio recipiente e substrato de preenchimento. Isso, segundo José et al. (2005), pode propiciar o desenvolvimento de mecanismos de tolerância às condições de campo, podendo contribuir para o aumento no desempenho pós-plantio.

Segundo Antoniazzi et al. (2013), têm-se preferido, de forma geral, nos plantios de recomposição florestal, mudas oriundas de sacos plásticos de grande volume, alegando-se que as maiores dimensões das mudas produzidas nesse sistema de produção acarretam maior sobrevivência e crescimento inicial após o plantio. Ferraz e Engel (2011), ao relatarem a preferência por mudas de maiores dimensões para plantios de recomposição florestal, mencionam que recipientes maiores implicam maiores custos de implantação, tanto pelo maior consumo de substratos e maior necessidade de espaço no viveiro como 
maior custo de transporte e menor rendimento de plantio. Sendo assim, com os resultados de sobrevivência obtidos pelas mudas oriundas de tubetes de $280 \mathrm{~cm}^{3}$ e a tendência de que o crescimento em campo se iguale após o plantio, pode-se inferir que mudas produzidas em tubetes de $280 \mathrm{~cm}^{3}$ também atendem às necessidades dos projetos de recomposição florestal.

Considerando que atualmente existe uma potencial tendência de verticalização das empresas que executam projetos de recomposição florestal, em que estas produzem as mudas florestais que utilizam em seus projetos, necessita-se de mais estudos relacionados à comparação de sistemas de produção. Esses estudos podem contribuir para a tomada de decisão dos empreendedores, principalmente quanto a que sistema de produção adotar ou do qual adquirir mudas.

\section{CONCLUSÃO}

- Para produção de mudas de Enterolobium contortisiliquum, podem-se utilizar sacos plásticos com capacidade de $1.248 \mathrm{~cm}^{3}$ ou tubetes de $280 \mathrm{~cm}^{3}$, pois ambos os tratamentos proporcionaram mudas de qualidade na fase de viveiro e apresentaram níveis aceitáveis de sobrevivência e crescimento inicial após o plantio.

\section{REFERÊNCIAS}

ANTONIAZZI, A. P.; BINOTTO, B.; NEUMANN, G. M.; SAUSEN, T. L.; BUDKE, J. C. Eficiência de recipientes no desenvolvimento de Cedrela fissilis Vell. (Meliaceae). Revista Brasileira de Biociências, Porto Alegre, v. 11, n. 3, p. 313 - 317, 2013.

AVILA, A. L.; ARAÚJO, M. M.; LONGHI, S. J.; GASPARIN, E. Caracterização da vegetação e espécies para recuperação de mata ciliar, Ijuí, RS. Ciência Florestal, Santa Maria, v. 21, n. 2, p. 251 260, 2011.

BELLOTO, A. Monitoramento das áreas restauradas como ferramenta para avaliação da efetividade das ações de restauração e para redefinição metodológica. In: RODRIGUES, R. R.; BRANCALION, P. H. S.; ISERNHAGEN, I. Pacto pela restauração da mata atlântica: referencial dos conceitos e ações de restauração florestal. São Paulo: LERF/ESALQ. 256 p. 2010.

BOMFIM, A. A.; NOVAES, A. B.; SÃO JOSÉ, A. R.; GRISI, F. A. Avaliação morfológica de mudas de madeira-nova (Pterogyne nitens Tull.) produzidas em tubetes e sacos plásticos e de seu desempenho no campo. Revista Floresta, Curitiba, PR, v. 39, n. 1, p. 33 - 40, 2009.

BRASIL. Ministério de Minas e Energia: Departamento Nacional da Produção Mineral. Projeto RADAM Brasil. Juremo: Geomorfologia, pedologias, vegetação e uso potencial da terra. Rio de Janeiro; 1980.

CARNEIRO, J. G. A. Produção e controle de qualidade de mudas florestais. Curitiba: Campos/UENF. UFPR/FUPEF, 1995. $451 \mathrm{p}$.

DUBOC, E.; GUERRINI, I. A. Crescimento inicial e sobrevivência de espécies florestais de galeria do domínio cerrado em resposta à fertilização. Energia na agricultura, Botucatu, v. 22, n. 1, p. 42 - 60, 2007.

DURIGAN, G.; SILVEIRA, E. R. Recomposição de mata ciliar em domínio cerrado, Assis, SP. Scientia Forestalis, Piracicaba, n. 56, p. 135 - 144, 1999.

FERRAZ, A. V.; ENGEL, V. L. Efeito do tamanho de tubetes na qualidade de mudas de jatobá (Hymenaea courbaril L. var. stilbocarpa (Hayne) Lee et Lang.), ipê-amarelo (Tabebuia chrysotricha (Mart. ex DC.) Sandl.) e guarucaia (Parapiptadenia rigida (Benth.) Brenan). Revista Árvore. Viçosa, v. 35, n. 3, p. 413 - 423, 2011.

GOMES J. M.; COUTO, L.; LEITE, H. G.; XAVIER, A. X.; GARCIA, S. L. R. Crescimento de mudas de Eucalyptus grandis em diferentes tamanhos de tubetes e fertilização N-P-K. Revista Árvore. Viçosa, v. 27, n. 2, p. 113 - 127, 2003. 
HAHN, C. M.; OLIVEIRA, C.; AMARAL, E. M.; RODRIGUES, M. S.; SOARES, P. V. Recuperação florestal: da semente à muda. São Paulo, SP: Secretaria do Meio Ambiente para a Conservação e Produção Florestal do Estado de São Paulo, 2006. 144 p.

JOSÉ, A. C.; DAVIDE, A. C.; OLIVEIRA, S. L. Produção de mudas de aroeira (Schinus terebinthifolius Raddi) para recuperação de áreas degradadas pela mineração de bauxita. Revista Cerne, Lavras. v. 11, n. 12, p. 187 - 196, 2005.

KELLER, L.; LELES, P. S. S.; OLIVEIRA NETO, S. N.; COUTINHO, R. P.; NASCIMENTO, D. F. Sistemas de blocos prensados para a produção de mudas de três espécies arbóreas nativas. Revista Árvore, Viçosa, v. 33, n. 2, p. 609 - 617, 2009.

LACERDA, D. M. A.; FIGUEIREDO, P. S. Restauração de matas ciliares do rio Mearim no município de Barra do Corda, MA: seleção de espécies e comparação de metodologias de reflorestamento. Acta Amazônica, Manaus, v. 39, n. 2, p. 295 - 304, 2009.

LIMA, A. L. S.; ZANELLA, F.; CASTRO, L. D. M. Crescimento de Hymenaea courbaril L. var. stilbocarpa (Hayne) Lee et Lang. e Enterolobium contortisiliquum (Vell.) Morong (Leguminosae) sob diferentes níveis de sombreamento. Acta Amazônica, Manaus, v. 40, n. 1, p. 43 - 48, 2010.

LONGHI, S. J.; ARAÚJO, M. M.; KELLING, M. B.; HOPPE, J. M.; MULLER, I.; BORSOI, G. A. Aspectos fitossociológicos de fragmentos de floresta estacional decidual, Santa Maria, RS. Ciência Florestal, Santa Maria, v. 10, n. 2, p. 59 - 74, 2000.

LOPES, J. L. W.; GUERRINI, I. A.; SAAD, J. C. C.; SILVA, M. R. Efeitos da irrigação na sobrevivência, transpiração e no teor relativo de água na folha em mudas de Eucalyptus grandis em diferentes substratos. Scientia Forestalis, Piracicaba, n. 68, p. 97 - 106, 2005.

MALAVASI, U. C.; KLEIN, J.; MALAVASI, M. M. E. Efeito de um protetor físico na semeadura direta de duas espécies florestais em área de domínio ciliar. Revista Árvore, Viçosa, v. 34, n. 5, p. 781 - 787, 2010.

MALAVASI, U. C.; MALAVASI, M. M. Efeito do volume do tubete no crescimento inicial de plântulas de Cordia trichotoma (Vell.) Arrab. ex Steud e Jacaranda micranta Cham. Ciência Florestal, Santa Maria, v. 16, n. 1, p. 11 - 16, 2006.

MARTINS, S. V. Recuperação de matas ciliares. Viçosa: Aprenda Fácil, 75 p. 2001.

MESQUITA, J. B.; SANTOS, M. J. C.; RIBEIRO, G. T.; MOURA, A. O. Avaliação da composição de substratos e recipientes na produção de mudas de jenipapo (Genipa americana L.). Natural Resources, Aquidabã, v. 1, n. 1, p. 37 - 45, 2011.

PORTUGAL, A. F.; COSTA, A. D. V.; COSTA, L. M.; SANTOS, B. C. M. Atributos químicos e físicos de um Cambissolo háplico Tb distrófico sob diferentes usos na zona da mata mineira. Revista Brasileira de Ciências do Solo, Viçosa, v. 32, n. 1, p. 249 - 258, 2008.

REIS, G .G.; REIS, M. G. F.; MAESTRI, M. Crescimento de Eucalyptus camaldulensis, Eucalyptus grandis e Eucalyptus cloeziana sob diferentes níveis de restrição radicial. Revista Árvore, v. 13, n. 1, p. 1 - 18, 1989.

SCALON, S. P. Q.; MUSSURY, R. M.; GOMES, A. A.; SILVA, K. A.; WATHIER, F.; SCALON FILHO, H. Germinação e crescimento inicial de muda de orelha-de-macaco (Enterolobium contortisiliquum (Vell.) Morong.): Efeito de tratamentos químicos e luminosidade. Revista Árvore, v. 30, n. 4, p. 529 - 536, 2006.

SENTELHAS, P. C.; PEREIRA, A. R.; MARIN, F. R. BHBRASIL: balanços hídricos climatológicos de 500 localidades brasileiras. Piracicaba: ESALQ, 1998. Disponível em: <http://www.lce.esalq.usp.br/ nurma.html>. Acesso em: 25/08/2012.

SILVA, B. M. S.; LIMA, J. D.; DANTAS, V. A. V.; MORAES, W. S.; SABONARO, D. Z. Efeito da luz no crescimento de mudas de Hymenaea parvifolia Huber. Revista Árvore, Viçosa, v. 31, n. 6, p. 1019 1026, 2007. 
SOUZA, D. M. S. Análise do comportamento de quatro espécies florestais expostas à luz solar plena oriundas de mudas produzidas em diferentes níveis de sombreamento. 2011. 45 f. Dissertação (Mestrado em Ciências Ambientais e Florestais) - Universidade Federal Rural do Rio de Janeiro, Seropédica.

THORNTHWAiTE, C. W.; MATHER, J. C. The water balance. Centeron: Drexel Institute of Technology, 1955. 104 p.

VILLA, E. B. Aspectos silviculturais e ecológicos em área de restauração florestal com diferentes espaçamentos de plantio. 2012. 57 f. Tese (Doutorado em Ciências Ambientais e Florestais) Universidade Federal Rural do Rio de Janeiro, Seropédica.

FLORESTA, Curitiba, PR, v. 45, n. 1, p. 141 - 150, jan. / mar. 2015. 
FLORESTA, Curitiba, PR, v. 45, n. 1, p. 141 - 150, jan. / mar. 2015. Abreu, A. H. M. de et al. 